\title{
Ductile Transition in Nylon-Rubber Blends: Influence of Water
}

\author{
R. J. GAYMANS, R. J. M. BORGGREVE, and A. B. SPOELSTRA, \\ Department of Chemical Technology, University of Twente, \\ P.O. Box 217, 7500 AE Enschede, The Netherlands
}

\begin{abstract}
Synopsis
On nylon 6 and nylon 6/EPDM blends the influence of water on the glass transition temperature, mechanical properties, and the ductile transition temperature was studied. Blends of $10 \%$ and $20 \%$ were prepared with a particle size of $0.3 \mu \mathrm{m}$ and the tensile properties, flexural moduli, tonsion moduli, and notched izod impact strength were studied as functions of water concentration. The ductile transition temperature in polyamides can be lowered by plasticizing the nylon and by a rubber particle-induced process; both processes show some synergistic effects.
\end{abstract}

\section{INTRODUCTION}

Polyamides are semiductile materials at room temperature (RT) in the dry state and above their glass transition temperature $\left(T_{g}\right)$ they are ductile. ${ }^{1-3} \mathrm{By}$ passing the glass transition, the yield strength of the nylon is lowered by a factor two $^{4}$ to four ${ }^{1}$ while the tensile strength changes some $30 \%$, and above the $T_{g}$, excessive yielding can take place. ${ }^{1-3}$ Thus at the $T_{g}$ a semiductile to ductile transition takes place.

There are two ways to lower this ductile transition temperature, one is by plasticizing the polyamide ${ }^{1-3}$ and the other is by blending with rubber. ${ }^{5-11}$ On wetting the nylon, the $T_{g}$ is lowered and the toughness at RT increases.

With rubber modification the impact properties of the nylons can greatly be improved. These blends show a ductile transition at a much lower temperature than the neat nylon. ${ }^{7}$ The ductile transition temperature of the blend depends on a number of factors such as rubber concentration, rubber particle size, and rubber modulus. ${ }^{7-11}$ The mechanism by which the blend deforms in the ductile region seems to be cavitation of the rubber and shear yielding between the cavities. ${ }^{8}$

Both methods of improving the impact behavior of the nylon seem to be based on quite different deformation mechanisms and the question arises whether these two mechanisms have synergistic effects.

\section{EXPERIMENTAL}

\section{Materials}

Nylon 6, type Akulon M258 was obtained from Akzo Plastics it had an $\eta_{\text {rel }}$ in $96 \% \mathrm{H}_{2} \mathrm{SO}_{4}$ of 5.8. EPDM rubber, type Keltan 740, was obtained from DSM Maleic Anhydride (MAh) was obtained from BDH Diisopropyl isobutyl peroxide (Perkadox 14) from Akzo Chemie. 
EPDM modification with maleic anhydride. A mixture of 100 parts EPDM, 2 parts MAh, and 0.025 parts Perkadox 14 was fed three times to a 19-mm Brabender single screw extruder, first with the barrel temperatures at $50^{\circ} \mathrm{C}$, the second time at $170^{\circ} \mathrm{C}$, and the third time at $250^{\circ} \mathrm{C}$. The MAh concentration as determined by endgroup titration was found to be $0.4 \%$.

Blend Preparation. The nylon-rubber blends were prepared on a $40-\mathrm{mm}$ Kautex single screw extruder which was fitted with a cavity transfer mixing head, zone temperatures of the barrel were $225^{\circ}, 225^{\circ}, 225^{\circ}$, and $230^{\circ} \mathrm{C}$. Test samples were prepared with an Arburg injection-molding machine, type 22155-250, zone temperatures of the barrel were $260^{\circ}, 260^{\circ}, 260^{\circ}$, and $260^{\circ} \mathrm{C}$.

Conditioning. The samples were conditioned in four ways: ${ }^{6}$

1. Drying in a vacuum oven at $110^{\circ} \mathrm{C}$ for one day (dry)

2. Boiling in a saturated potassium acetate solution for one day $(\sim 50 \%$ relative humidity, $\mathrm{RH}$ )

3. Boiling in a saturated sodium phosphate solution for one day ( $\sim 65 \% \mathrm{RH})$

4. Boiling in water for one day $(\sim 100 \% \mathrm{RH})$

Tensile tests were carried out on dumbbell-shaped samples (DIN 53455, specimen type 4) with a deformation speed of $250 \% / \mathrm{min}$.

The flexural moduli were determined according to ISO 178. The torsion moduli were determined at a frequency of $1 \mathrm{~Hz}$ and a heating rate of $0.5^{\circ} \mathrm{C} / \mathrm{min}$ with a Myrenne ATM3. The notched izod impact test was carried out according to ISO 180 , specimen type 1 , notch type A. The particle size of the dispersed rubber in the blend was measured on cut surfaces with a scanning electron microscope. For this the cutted injection-molding bars were treated $16 \mathrm{~h}$ with boiling xylene, dried overnight in a vacuum oven at $110^{\circ} \mathrm{C}$, and coated with gold.

\section{RESULTS AND DISCUSSION}

\section{Water Absorption}

The water absorption data of the materials are given in Table I. The blends absorb somewhat less water than the nylon. If assumed that the EPDM

TABLE I

Water Absorption Data

\begin{tabular}{llcc}
\hline & & $\begin{array}{c}\text { Water } \\
(\text { \%) }\end{array}$ & $\begin{array}{c}\text { Water in nylon } \\
(\text { () })\end{array}$ \\
\hline Sat. potassium acetate & nylon & 2.3 & 2.3 \\
& B10 & 2.2 & 2.4 \\
Sat. sodium phosphate & B20 & 1.8 & 2.2 \\
& nylon & 7.8 & 7.8 \\
Water & B10 & 6.8 & 7.6 \\
& B20 & 6.2 & 7.7 \\
& nylon & 11.6 & 11.6 \\
& B10 & 10.4 & 11.6 \\
\hline
\end{tabular}


rubber absorbs little water, the water concentration in the nylon phase can be calculated and found to be as high as in the neat nylon. From this it is expected that the dimensional stability of the blends improves with the volume fraction of the rubber.

\section{Structure}

The rubber in the blends is in the form of dispersed particles with a weight-average particle size of $0.3 \mu \mathrm{m}$ for both blends. This size compares well to the particle sizes in industrial nylon rubber blends.

\section{Tensile Properties}

The tensile strength of all these materials decreases as they absorb water (Fig. 1). Blends have a lower tensile strength than nylon both dry and wet.

Elongation at break increases on wetting, and blends were found to have a lower elongation at break than nylon. The high elongations at break of the dry materials is due to the high molecular weight of the nylon.

\section{Flexural Modulus}

The flexural modulus decreases strongly on wetting. As the nylon is wetted the $T_{g}$ is lowered from above to below room temperature. The tailing off of the moduli at the highest water concentrations suggest that the glass transition temperature has been exceeded.

\section{Torsion Moduli}

In Figure 2, the $G^{\prime}$ of the nylon and both dry and wetted blends are given. The behavior of nylon is well known. ${ }^{1}$ Water increases the low temperature moduli and shifts the $T_{g}$ to a lower temperature. The difference between the $7.7 \%$ and $11.7 \%$ water content samples is small and the moduli above the $T_{8}$ are only slightly affected by its presence.

The blends have an extra transition at $-55^{\circ} \mathrm{C}$, related to the $T_{g}$ of the EPDM rubber. On wetting the blends, the $T_{g}$ of the rubber seem to increase slightly, possibly due to the approaching nylon transition.

\section{Impact Behavior}

Dry nylon has a ductile transition at $80^{\circ} \mathrm{C}$ and a semiductile behavior at RT and $-40^{\circ} \mathrm{C}$ (Fig. 3). On wetting, the ductile transition shifts to lower temperatures (for the $11.7 \%$ water sample to $-30^{\circ} \mathrm{C}$ ), the notched Izod at RT increases to very high values and the Izod at $-40^{\circ} \mathrm{C}$ increases from 2.9 to 5.7 $\mathrm{kJ} / \mathrm{m}^{2}$.

In its dry state, $\mathrm{B} 10$ material has a ductile transition at $17^{\circ} \mathrm{C}$, and below that temperature is still quite tough $\left(\operatorname{Izod}\right.$ at $-40^{\circ} \mathrm{C}$ is $\left.9.3 \mathrm{~kJ} / \mathrm{m}^{2}\right)$. On wetting, the ductile transition is shifted to lower temperatures but the low temperature impact value changes are minor.

Ductile transition of dry-state $\mathrm{B} 20$ is $-17^{\circ} \mathrm{C}$, and its notched impact strength at $-40^{\circ} \mathrm{C}$ is $13 \mathrm{~kJ} / \mathrm{m}^{2}$. Wetting this material changes the impact behavior slightly at the highest water concentrations. 


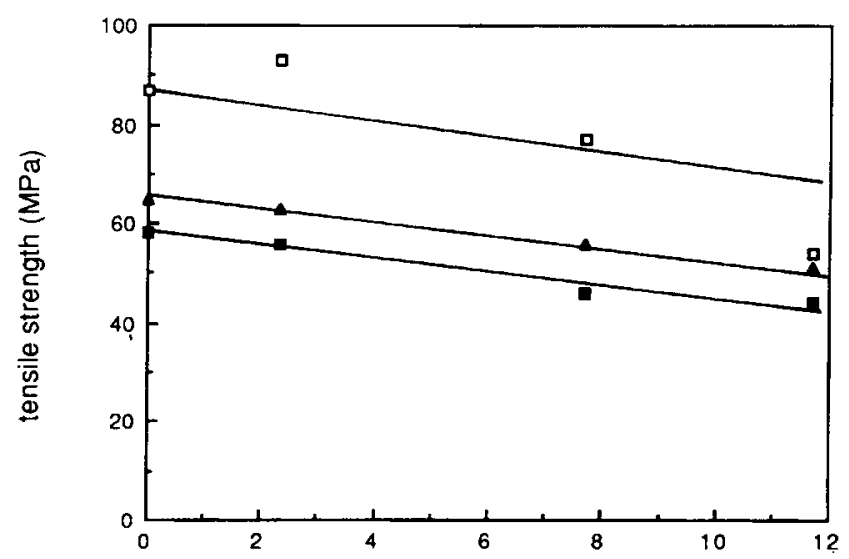

(a)

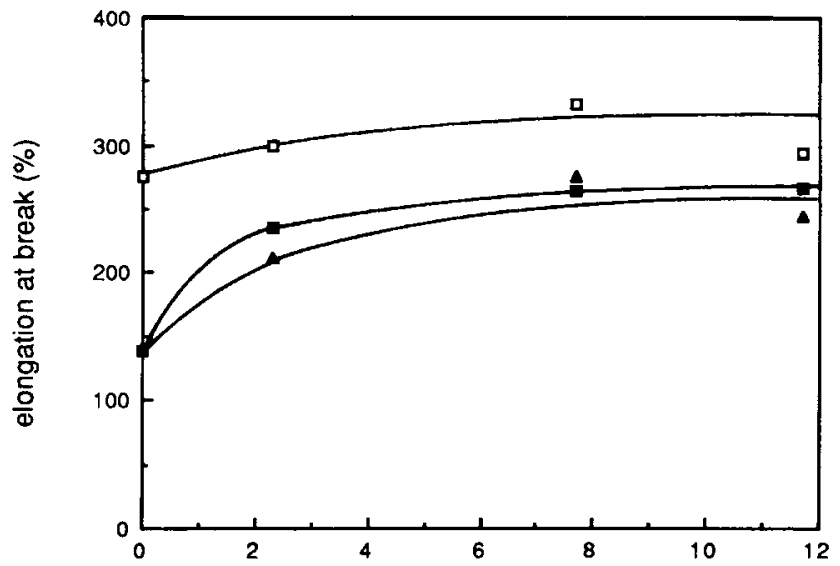

(b)

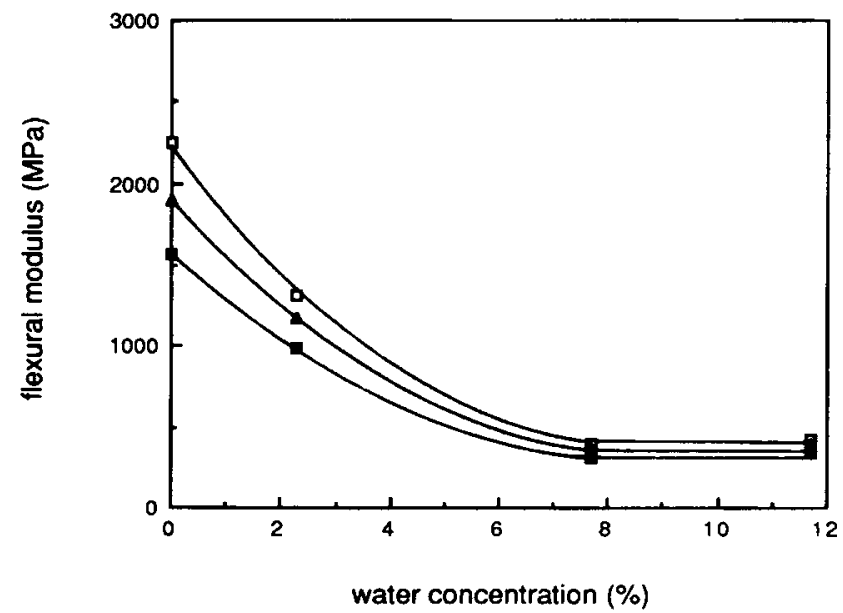

(c)

Fig. 1. Tensile strength, elongation at break and flexural modulus as function of water concentration in the nylon phase: $\square$, Nylon $6 ; A, B 10 ; \square, B 20$. 


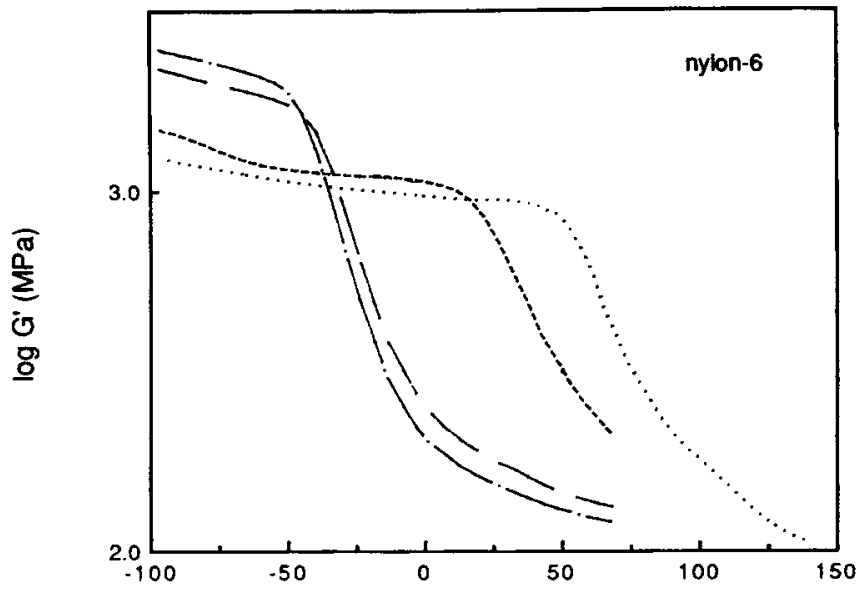

(a)

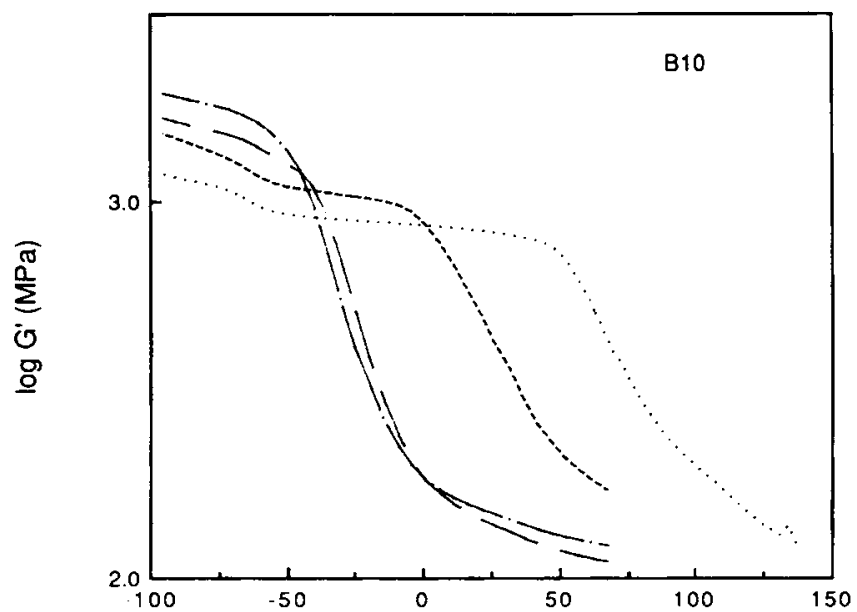

(b)

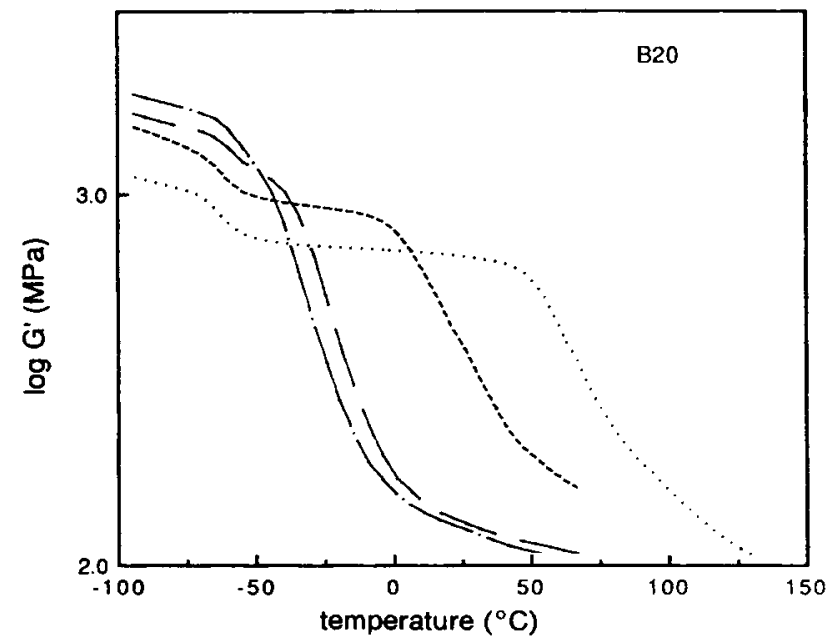

(c)

Fig. 2. Torsion moduli $\left(G^{\prime}\right)$ as function of temperature at the water concentrations: $\cdots$, dry; ,$--- 2.3 \% ;--, 7.6 \% ;-\cdot-, 11.6 \%$. 


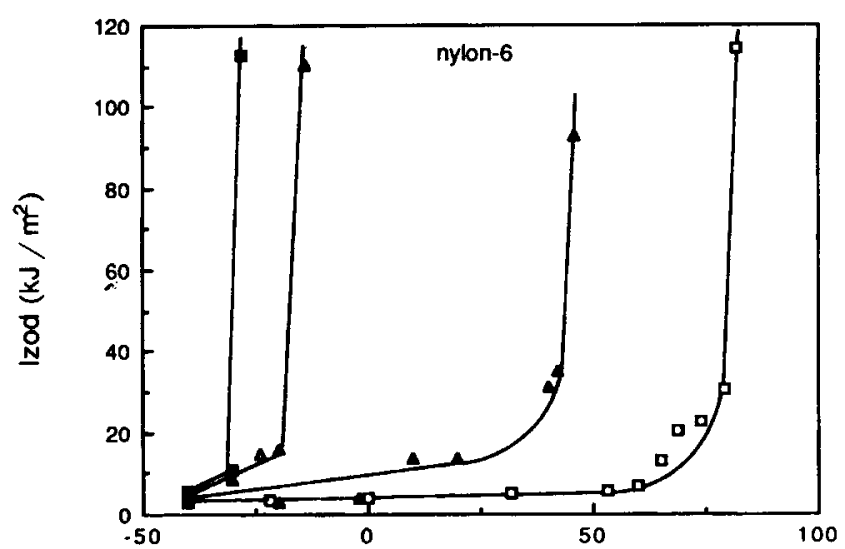

(a)

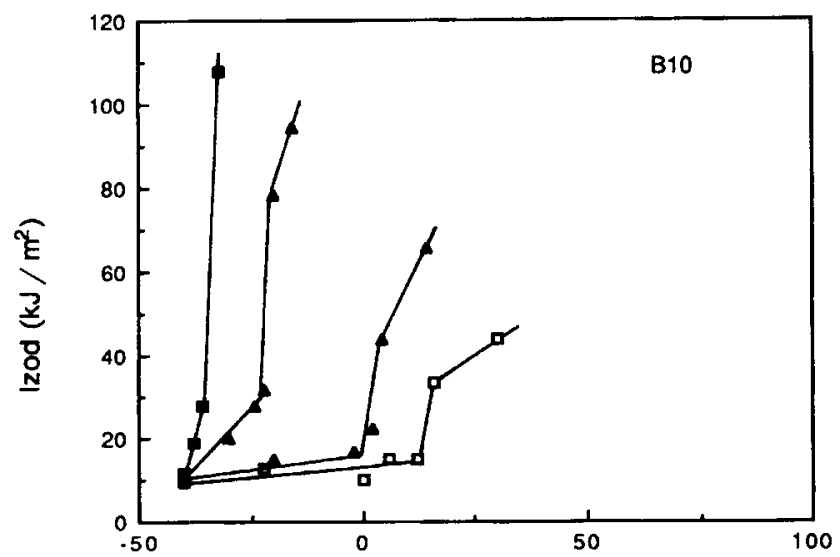

(b)

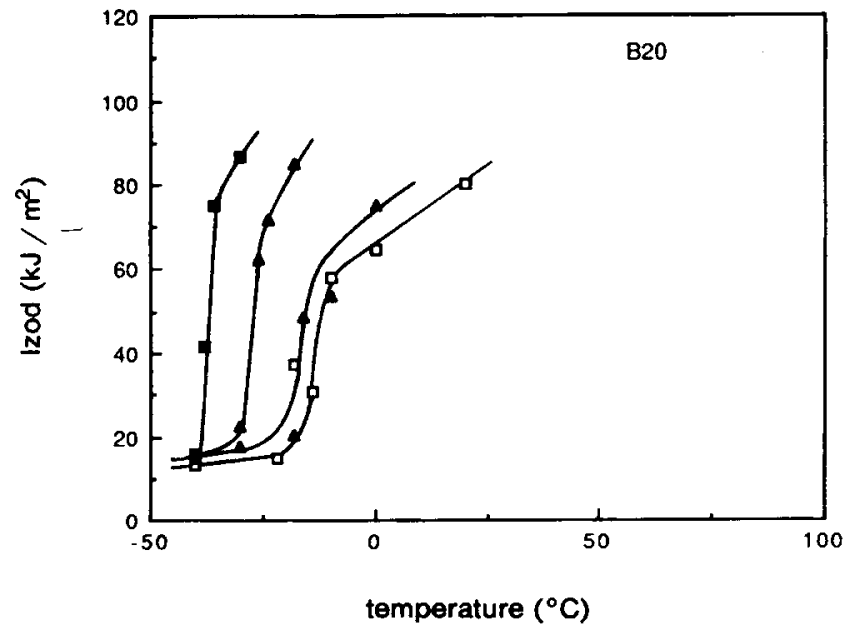

(c)

Fig. 3. Notched Izod impact strength as function of temperature at the water concentrations in the nylon phase of: $\square$, dry; $\Delta, 2.3 \% ; \triangle, 7.6 \% ; \square, 11.6 \%$. 


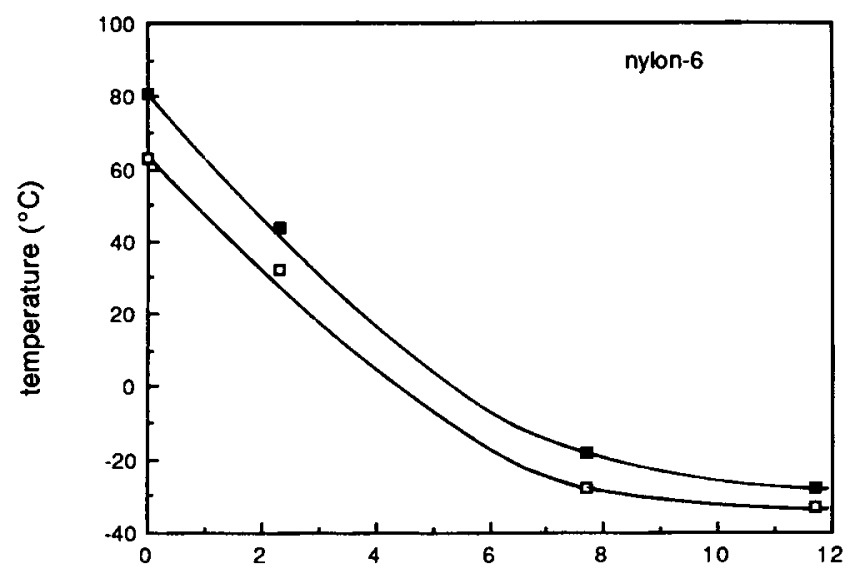

(a)

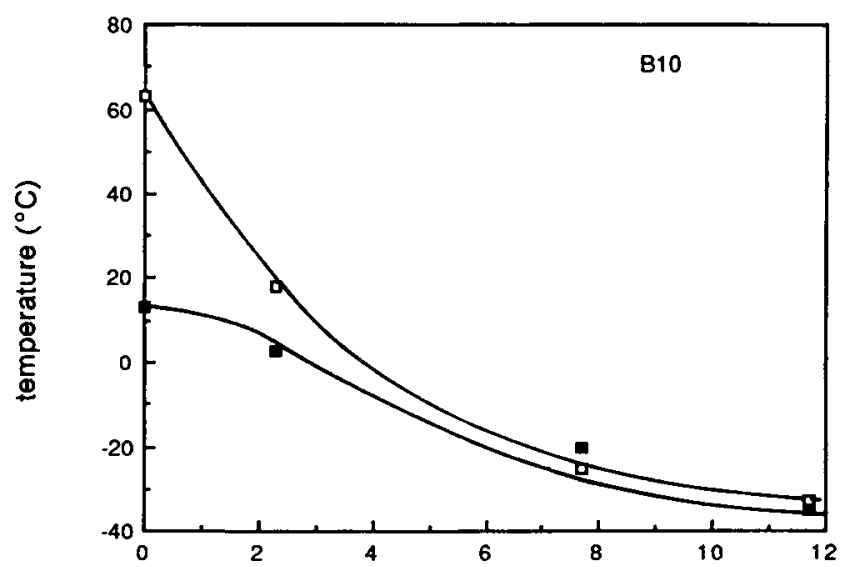

(b)

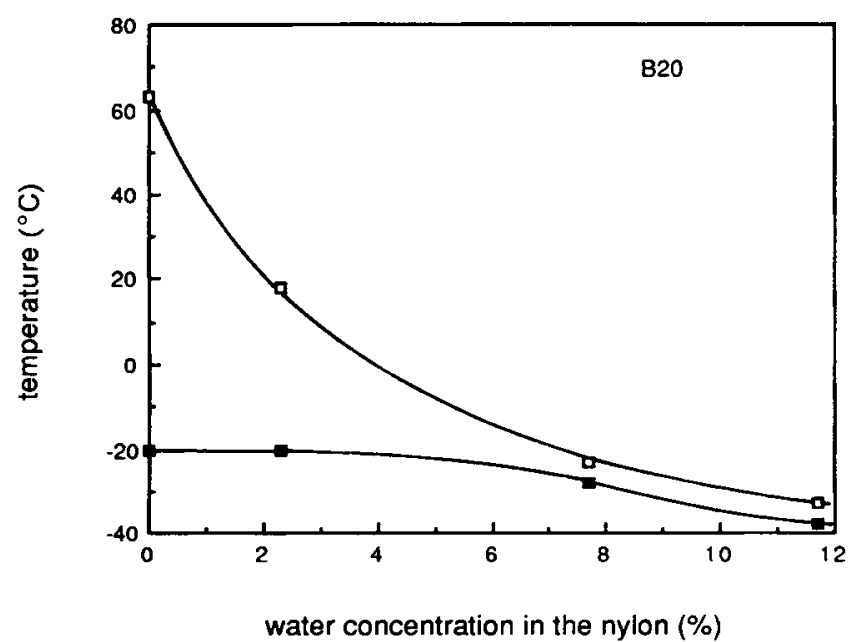

(c)

Fig. 4. Influence of water concentration on the transition temperatures $\left(\square, T_{g}\right)$, ( $\square$ ) ductile transition. 
Both the glass and ductile transitions are dependent on water concentration. Figure 4 plots both as a function of water concentration. In the neat nylon, the ductile transition is $10-15^{\circ} \mathrm{C}$ higher than the glass transition temperature range. In the neat nylon, both processes are clearly coupled.

Dry-state ductile transition of $10 \%$ and $20 \%$ blends occurs at a much lower temperature than the glass transition. On wetting these blends, the $T_{g}$ is lowered and the ductile transition is influenced gradually. There are clearly two processes involved for blends: one well below the $T_{g}$ of the blend and one coupled to the $T_{g}$. Compared to the dry blends, the wetted blends have a higher impact strength in the ductile region, and compared to the neat nylon, a slightly lower ductile transition and a higher impact strength in the semi-ductile region.

Clearly both types of mechanisms which induce the ductile transition in polyamides have some synergistic effects.

This work is part of the research program of the University of Twente and was financially supported by The Netherlands Technology Foundation (STW).

\section{References}

1. R. Vieweg and A. Muller, Kunststoffe Handbuch, Part VI, Polyamide, Carl Hanser Verlag, Munchen, 1966, Chap. 4.

2. R. M. Ogorkiewicz, Engineering Properties of Plastics, John Wiley \& Sons, New York, 1973.

3. M. L. Kohan, Nylon Plastics, SPE Monograph, John Wiley \& Sons, New York, 1973.

4. B. Hartman and R. F. Cole, Polym. Eng. Sci., 25, 65 (1985).

5. E. A. Flexmann, Kunststoffe, 69, 172 (1979).

6. M. T. Hahn, R. W. Hertzberg, and J. A. Masson, J. Mat. Sci., 18, 3551 (1983).

7. R. J. M. Borggreve, R. J. Gaymans, J. F. Ingen Housz, and J. Schuijer, Polymer, 28, 1489 (1987).

8. R. J. M. Borggreve, R. J. Gaymans, and A. R. Luttmer, Makromol. Chem., Macromol. Symp., 16, 195 (1988).

9. S. Wu, J. Polym. Sci. Polym Physics Ed., 21, 699 (1983).

10. S. Wu, Polymer (Lond.), 261855 (1985).

11. F. Fahler and J. Merten, Kunststoffe, 75, 157 (1985).

Received February 12, 1988

Accepted February 24, 1988 